\title{
Example Application of LGGH High-efficiency Coal-fired Flue Gas Treatment Technology in Yudian Dabu Power Plant
}

\author{
Liao Zeng'an ${ }^{1, ~ *, ~ L u o ~ R u s h e n g ~}{ }^{2}$, Lin Xiang ${ }^{3}$, Xie Qingliang ${ }^{4,}$ * \\ ${ }^{1}$ ESP and DE-NOx Engineering Co., Fujian Longking Co., Ltd., Longyan City, China \\ ${ }^{2}$ Fujian Longking Co., Ltd., Longyan City, China \\ ${ }^{3}$ Electric Precipitation and Denitrification Division and VOCs Development Department, Fujian Longking Co., Ltd., Longyan City, China \\ ${ }^{4}$ Electric Precipitation and Denitrification Division and Research \& Development Department, Fujian Longking Co., Ltd., Longyan City, China
}

Email address:

13959028896@139.com (Liao Zeng'an), 1kluorsh163@139.com (Luo Rusheng), 13860203302@139.com (Lin Xiang),

13860216529@139.com (Xie Qingliang)

${ }^{*}$ Corresponding author

\section{To cite this article:}

Liao Zeng'an, Luo Rusheng, Lin Xiang, Xie Qingliang. Example Application of LGGH High-efficiency Coal-fired Flue Gas Treatment Technology in Yudian Dabu Power Plant. American Journal of Electrical Power and Energy Systems. Vol. 8, No. 2, 2019 , pp. 56-61. doi: $10.11648 /$ j.epes.20190802.13

Received: February 21, 2019; Accepted: April 15, 2019; Published: May 17, 2019

\begin{abstract}
This paper describes the severe air pollution and ultra-low emission process route in China today, based on which it studies and analyzes the LGGH high-efficiency coal-fired flue gas treatment technology applicable to the upgrading of the ultra-low emission with respect to its origin, composition, characteristics and advantages. Then this paper gives a case study on the application of this technology in Yudian Dabu Power Plant where ultra-low emission is required, in particular the project profile of Yudian Dabu Power Plant, and specific proposal, process layout, main design parameters, technical features and operating result of the technology in the power plant. According to the testing, after this technology is put into use in the plant, the dust and $\mathrm{SO}_{3}$ emissions of Unit 2\# chimney drop to $2.3 \mathrm{mg} / \mathrm{m}^{3}$ and $2.4 \mathrm{mg} / \mathrm{m}^{3}$ respectively, much lower than the national ultra-low emission limits. All these can demonstrate that the large-scale coal-fired power units can achieve a significant result by adopting the optimized LGGH high-efficiency coal-fired flue gas treatment technology, this technology provides higher precipitation efficiency, energy conservation and emission reduction, and high-efficiency $\mathrm{SO}_{3}$ removal, solves the problem of "Gypsum rain" and visual pollution, and realizes dry chimney discharge, indicating that this technology deserves promotion and has great potential to become a popular post-combustion flue gas treatment technology.
\end{abstract}

Keywords: Low-Low Temperature, LGGH, Dabu Power Plant, Example Application

\section{Introduction}

In recent years, haze has frequented the Beijing-Tianjin-Hebei region and the Yangtze River Delta, and people attach increasing importance to environmental protection. As a major consumer of coal and main source of air pollutants, coal-fired power plants now are key objects for national control. In July 2011, the Ministry of Environmental Protection issued Emission Standard of Air Pollutants for Thermal Power Plants [1], which puts forward strict requirements for emission of air pollutants of thermal power plants; according to this Standard, the smoke emission shall be limited within $20 \mathrm{mg} / \mathrm{Nm}^{3}$ in key control areas. In September 2014, the National Development and Reform Commission, the Ministry of Environmental Protection and the National Energy Administration jointly issued Action Plan for Upgrading and Transformation of Energy Conservation and Emission Reduction of Coal Power [2], which even requires clean emission nearby the gas units of coal-fired power plants.

Although China is always adjusting the national energy structure and the proportion of the coal in the primary energy drops continuously, China's coal-centered resource consumption structure will continue in essence in a short time 
[3-6] and coal combustion is still a main source of air pollution for China in future. As national and local policies for ultra-low emission are issued successively, upgrading and transformation of coal-fired power plants for ultra-low emission remains the key direction of environmental protection in power industry in future. Currently, the technology for post-combustion flue gas treatment or ultra-low emission varied greatly. In this context, to select a high-efficiency, economic and comprehensive emission technology becomes an urgent task for emission treatment of coal-fired power plants.

Yudian Dabu Power Plant is a newly-built plant, which has finished the construction drawing and most of on-site construction before the issuance of Action Plan for Upgrading and Transformation of Energy Conservation and Emission Reduction of Coal Power. Unfortunately, the originally-planned desulphurization and precipitation system has a design flue-gas emission of $20 \mathrm{mg} / \mathrm{Nm}^{3}$ at the outlet of chimney, far from the $10 \mathrm{mg} / \mathrm{Nm}^{3}$ as stipulated. To avoid the risk of overlapping investment, prolonged construction period and power loss after the start of power generation and to achieve the goal of ultra low emission, we optimized the technology scheme in light of the original design and construction schedule and based on the local conditions.

\section{Introduction to LGGH High-Efficiency Coal-Fired Flue Gas Treatment Technology}

\subsection{Origin}

In 2009, Long Hui [7] first introduced the concept of low-low-temperature high-efficiency flue gas treatment to China and briefed the origin of this technology. According to his study, Mitsubishi has taken the lead in low-low-temperature high-efficiency coal-fired flue gas treatment and developed the Mitsubishi recirculated non-leak type gas-gas heater (MGGH) in response to Japan's increasing requirements for environmental protection. The process flow of a MGGH is shown in Figure 1.

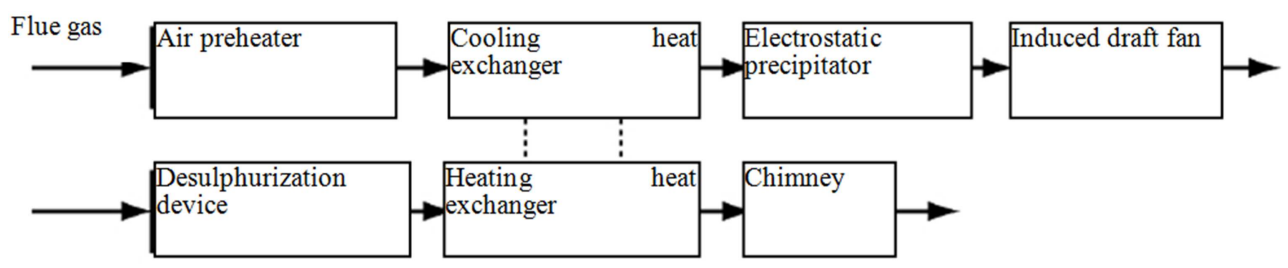

Figure 1. Process flow of Mitsubishi Recirculated Non-leak Type Gas-Gas Heater.

Being highly efficient in precipitation, energy- and watersaving and freeing the chimney from the ugly "Tail", MGGH is widely applied in Japan's thermal power units. According to a rough statistics, the total capacity of the coal-fired generating units equipped with the low-low-temperature high-efficiency coal-fired flue gas treatment technology in Japan has reached $6500 \mathrm{MW}$ at present. This technology had also attracted the attention of Liao Zeng'an, a Chinese scholar. Based on the specific situation of the coal-fired generating units in China, Liao [8] proposed another LGGH high-efficiency coal-fired flue gas treatment technology-Longking Gas Gas Heater (LGGH). The specific process flow is shown in Figure 2.

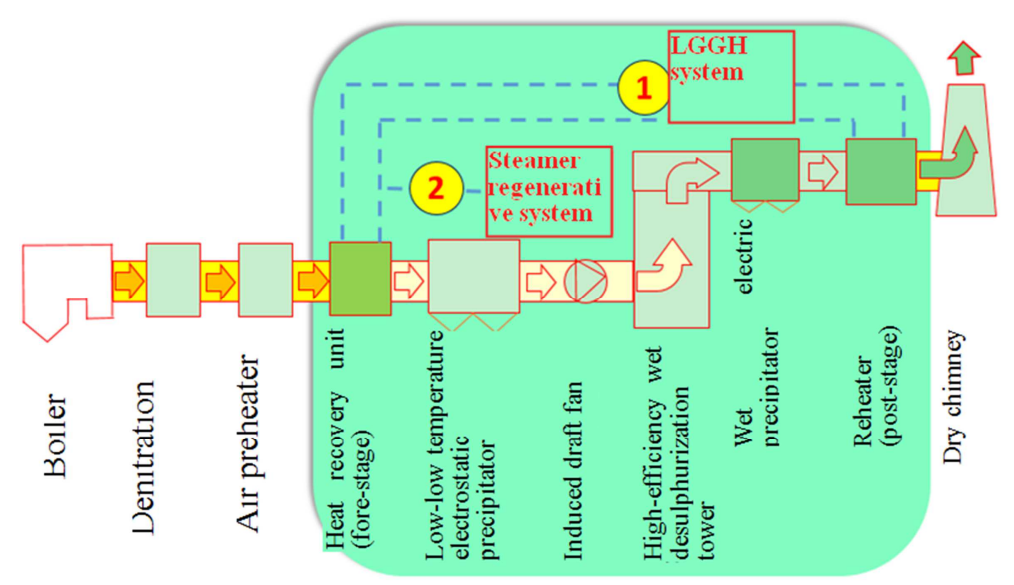

Figure 2. Process flow diagram of LGGH high-efficiency coal-fired flue gas treatment technology.

\subsection{Features and Advantages}

The LGGH high-efficiency coal-fired flue gas treatment technology has the following features:

\subsubsection{Enhancing the Efficiency of Precipitation, Saving Energy and Reducing Emission}

LGGH has a fore-stage heat exchanger to enable the electrostatic precipitator to efficiently treat the flue gas at an 
operating temperature of about $90^{\circ} \mathrm{C}$, a low-low temperature for flue gas treatment. Compared with dust at the normal operating temperature $\left(120 \sim 150^{\circ} \mathrm{C}\right)$, dust at this low-low temperature has a lower specific resistance, a least one order of magnitude lower; consequently, the electrostatic precipitator could have higher efficiency in precipitation. Since the flue gas temperature lower down, the volume of flue gas to be treated by the precipitator is reduced; therefore, the same precipitator could go further up in the efficiency of precipitation and reduce the emission of dust. Meanwhile, with the reduced volume of the flue gas flow, the power consumption of the induced draft fan goes down. Taken together, the LGGH ensure higher precipitation efficiency, energy conservation and emission reduction.

\subsubsection{Effectively Removing $\mathrm{SO}_{3}$ and Relieving the Downstream Device from Corrosion}

With LGGH high-efficiency coal-fired flue gas treatment technology, the flue gas treatment temperature is reduced to below the acid dew point; hence, $\mathrm{SO}_{3}$ could convert to $\mathrm{H}_{2} \mathrm{SO}_{4}$ and get condensed. Because of the high content of dust at the inlet of the precipitator, the condensed $\mathrm{H}_{2} \mathrm{SO}_{4}$ could be absorbed by the dust in a large area and get collected along with the dust by the LGGH precipitator. A previous study has shown that, when the dust-sulphur ratio $(\mathrm{D} / \mathrm{S})$ is higher than 100 , the removal rate of SO3in the flue gas can be up to $95 \%$ [9-10]. With the removal of $\mathrm{SO}_{3}, \mathrm{LGGH}$ could relieve the downstream device from corrosion.

\subsubsection{Saving the Water Consumption for Desulphurization and Enhancing the Efficiency of the Desulphurization System}

LGGH could reduce the flue gas temperature at the desulphurization entrance to a temperature $30 \sim 40^{\circ} \mathrm{C}$ lower than the flue gas temperature under normal treatment, a low-low temperature. Now that the flue gas temperature decreases, accordingly, the water consumption for desulphurization and the washing slurry temperature will reduce and the desulphurization efficiency will increase. Meanwhile, the LGGH electrostatic precipitator, with its high precipitation efficiency, could protect the gypsum of the desulphurization system from being polluted by the excessive dust, which could damage the dehydration performance of the gypsum [11-12].

\subsubsection{Good Adaptability and High Economy of the Coal Type}

LGGH high-efficiency coal-fired flue gas treatment technology could change the property of the flue gas in an active manner and thus improve the performance of the device. In addition, it could adapt to a wide range of coals. As it raises the precipitation efficiency in the upstream process, it could also create favorable working condition for the downstream devices. In the upstream process, it strengthens the precipitation, removes $\mathrm{SO}_{3}$, reduces the power consumption of the induced draft fan, remits the $\mathrm{SO}_{3}$ corrosion, and ensures the performance of the gypsum. With LGGH, Flue Gas Desulfurization (FGD) is no more hampered by $\mathrm{SO}_{3}$ corrosion, which could save the large amount of money for corrosion, maintenance, and repair. Besides, the post-stage heat exchanger of the LGGH at the downstream will heat the flue gas to a rational temperature level; thus improving the working environment of the wet chimney, realizing dry chimney discharge, reducing the possibility of "Gypsum rain", helping get rid of the unsightly "Smoke plume", etc.

\subsubsection{No Leakage and Comprehensive Utilization of Heat Energy}

With the sealed heat transferring tube, LGGH high-efficiency coal-fired flue gas treatment technology could effectively avoid leakage and make full use of the heat; therefore, LGGH does not have such troubles as blockage, leakage and easy excessive emissions that exists in the conventional rotary GGHs. Depending on the actual situations of the coal-fired units in China, the recovered heat may be used in the flue gas reheating system, the condensate system and the heating system.

\section{Example Application}

\subsection{Project Profile}

As a key energy construction project of "Twelfth-Five-Year Plan" in Guangdong Province, Yudian Dabu Power Plant adopts state-of-the-art environmental protection technology to construct two 660MW ultra-supercritical coal-fired generating units according to the principle of "Constructing large units and shutting down small units". The design annual generation of the two units is $60 \times 10^{8} \mathrm{kw}$, the output value is CNY $30 \times 10^{8}$ and the annual tax can reach CNY $4 \times 10^{8}$. These two units not only guarantees the power supply for the region, but also drives the economic and social development of the old revolutionary base area and the former central Soviet region in Dabu and powers up the revitalization and development of Meizhou. Targeting at constructing a benchmarking power plant in the mountainous area, Dabu Power Plant is constructed with the desulphurization, denitration and precipitation facilities synchronously, and the construction fund for the energy conservation and environmental protection facilities is nearly RMB $6.2 \times 10^{8}$, accounting for $12 \%$ of the total investment for the Project. On as received basis, the design coal for the project has a sulphur content of $1.03 \%$ and an ash content of $25.09 \%$, both of which are middle level; therefore, the requirement for the desulphurization and precipitation equipment is relatively high to meet the national standard of ultra low emission.

\subsection{Selection of Technology and Introduction to Scheme}

Following the construction requirement and the national and local policies, Yudian Dabu Power Plant fully taps the potential to control pollutant emission and strives to become benchmarking power plant in the mountainous area. After the issuance of Action Plan for Upgrading and Transformation of Energy Conservation and Emission Reduction of Coal Power, Dabu Power Plant is always confused about which post-combustion flue gas treatment technology to select. 
Through a comprehensive comparison and analysis, in light of the good effect the Units $5 \#$ and $6 \#$ of the existing plant (Meixian Power Plant) has obtained after low-low-temperature transformation, Dabu Power Plant finally choose LGGH high-efficiency coal-fired flue gas treatment technology. Since it is the first time that LGGH high-efficiency coal-fired flue gas treatment technology has been applied in a large infrastructure project of coal-fired generating units in China, in order to further determine the reliability of the technology, the relevant technical personnel on behalf of the Employer and the Design Institute further investigate on international successful cases. The actual good application effects further strengthen the confidence of using LGGH high-efficiency coal-fired flue gas treatment technology in Dabu Power Plant.

The process flow of LGGH high-efficiency coal-fired flue gas treatment technology in YudianDabu Power Plant is shown in Figure 3.

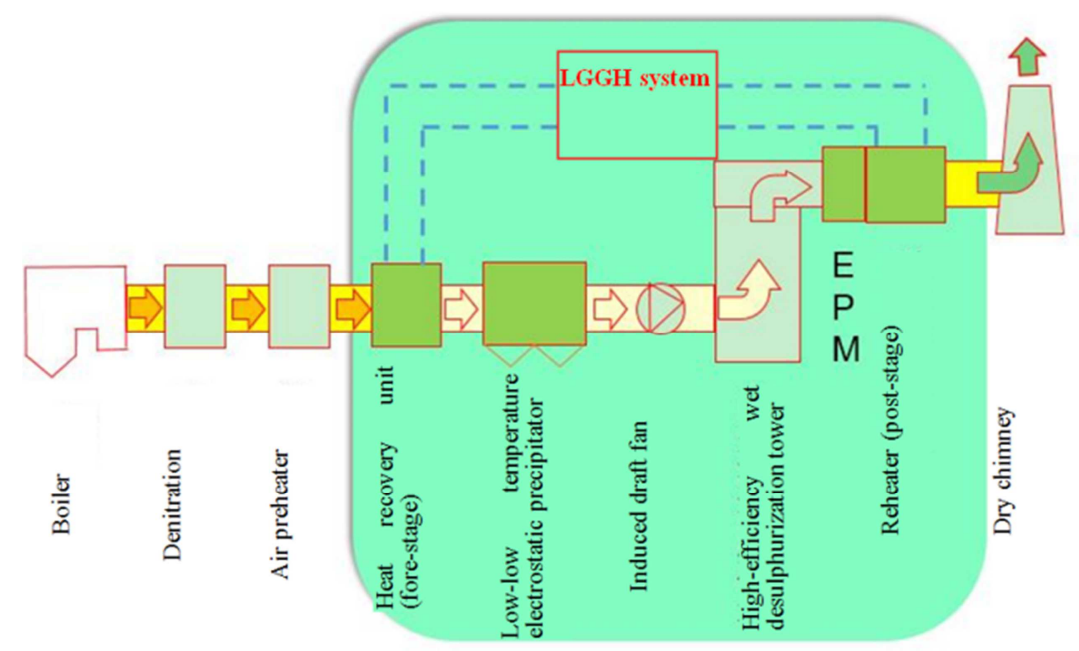

Figure 3. Process flow of LGGH high-efficiency coal-fired flue gas treatment technology in Dabu Power Plant.

At the same time, in consideration of the device integrity, the uniformity of the gas flow and the device stability within the whole plant, the LGGH-related devices are subjected to 3D design and optimized according to the design of the flue. The general layout of LGGH high-efficiency coal-fired flue gas treatment technology is shown in Figure 4.

The main design parameters of LGGH high-efficiency coal-fired flue gas treatment technology are shown in the following Table 1:

Table 1. Main design parameters.

\begin{tabular}{|c|c|c|c|c|}
\hline $\mathbf{S} / \mathbf{N}$ & Description & Unit & Value and result & Remarks \\
\hline 1 & Unit capacity & MW & 660 & \\
\hline 2 & Design flue gas treatment capacity of LGGH & $\mathrm{Nm}^{3} / \mathrm{h}$ & 2005375 & \\
\hline 3 & Design inlet flue gas temperature of the heat recovery unit & ${ }^{\circ} \mathrm{C}$ & 125 & \\
\hline 4 & Design outlet flue gas temperature of the heat recovery unit & ${ }^{\circ} \mathrm{C}$ & 90 & \\
\hline 5 & Design inlet concentration of the low-low-temperature electrostatic precipitator & $\mathrm{g} / \mathrm{m}^{3}$ & 26.15 & \\
\hline 6 & Design outlet concentration of the low-low-temperature electrostatic precipitator & $\mathrm{mg} / \mathrm{m}^{3}$ & 50 & \\
\hline 7 & Design precipitation efficiency of the low-low-temperature electrostatic precipitator & $\%$ & 99.85 & \\
\hline 9 & Design inlet concentration of the EPM & $\mathrm{mg} / \mathrm{m}^{3}$ & $\leq 19.5$ & \\
\hline 10 & Design outlet concentration of the EPM & $\mathrm{mg} / \mathrm{m}^{3}$ & $\leq 10$ & \\
\hline 11 & Design inlet temperature of the reheater & ${ }^{\circ} \mathrm{C}$ & 48 & \\
\hline 12 & Design outlet temperature of the reheater & ${ }^{\circ} \mathrm{C}$ & 80 & \\
\hline
\end{tabular}

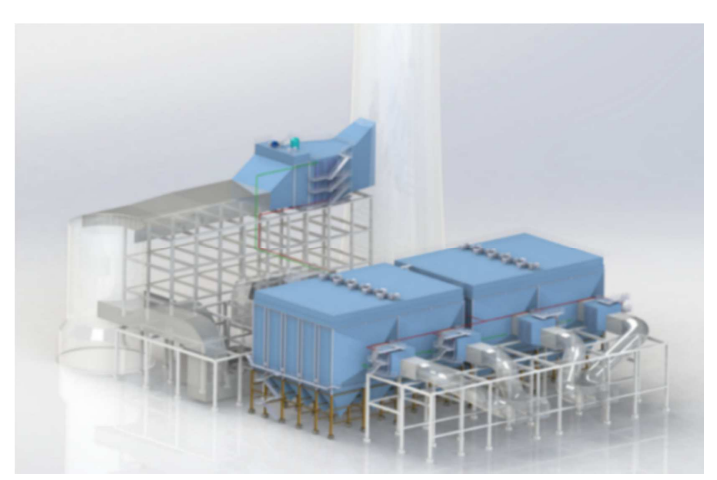

Figure 4. General layout of Longking Gas Gas Heater in Dabu Power Plant.

\subsection{Technical Features}

Combined with the actual features of Dabu Power Plant, the LGGH is subjected to improvements and optimizations at the technology implementation stage. Compared with traditional low-low-temperature high-efficiency coal-fired flue gas treatment technologies, the LGGH applied in Dabu Power Plant is a technical innovation:

i. Since the gas volume and temperature varies among the flues for the existing rotary air preheater, a differential design was applied for the fore-stage heat exchanger of the LGGH to ensure a uniform flue gas temperature at 
the inlet of the low-low-temperature electrostatic precipitator. The structure of the fore-stage heat exchanger is selected and designed rationally according to the practical parameters, so as to guarantee low-low-temperature high-efficiency operating conditions.

ii. After confirming the application scheme of the LGGH high-efficiency coal-fired flue gas treatment technology, the power plant, the LGGH-related devices were designed together with the flue and the desulphurization tower as a whole by joint work of the Plant, the Design Institute and the Manufacture. Besides, a uniform distribution model for gas flow was built to guarantee the uniformity of the gas flow distribution within the whole equipment. After the optimization, the resistance of the flue gas reduced by above 500Pa.

iii.To achieve ultra-low emission, an Electrostatic Precipitator \& Mist eliminator (EPM) is provided creatively to realize thorough precipitation and capture of droplets. The EPM was deigned integrated to the post-stage heat exchanger of the LGGH, which saves the floor space and gives full play to the joint function of thorough precipitation and demisting. On January, 2017, the Nanjing Power Equipment Quality and Performance Testing Center tested the Unit 2\#. It was found that the EMP of Unit $2 \#$ was $65.7 \%$, the $\mathrm{SO}_{3}$ removal rate $32 \%$, the droplet removal rate $62.2 \%$. In contrast with the conventional wet electrostatic precipitator, the dust collecting area of the EMP is $1 / 9$ that of the former; in this way, the two boilers could save RMB 36,000,000 in equipment investment, $930 \mathrm{~kW}$ in power consumption and RMB $2,550,000 /$ year in electric charge.

\subsection{Operation Features and Effects}

LGGH high-efficiency coal-fired flue gas treatment system is an integrated system with self-adaption control. Provided with such initial data as flue gas temperature, flue gas volume, VA characteristic curves, back corona index and smoke turbidity changes, it could automatically adjust the total heat exchange amount of the flue gas and the flue gas temperature after heat exchange in light of an analysis and comparison with the preset benchmark. For this reason, LGGH could ensure the low gas temperature and the best operating conditions for the precipitator, a guarantee for balanced flue gas temperature and high-efficiency performance.

Meanwhile, to achieve the temperature raise as required for the post-stage heat exchanger of the LGGH at a low load, the system is equipped with an auxiliary heater. The auxiliary heater could replenish the system with heat by using part of the steam; therewith, the system could guarantee full-load dry chimney discharge, reduce the possibility of "Gypsum rain", help get rid of the effect of "Smoke plume". The actual commissioning effect of LGGH in Yudian Dabu Power Plant is shown in Figure 5.

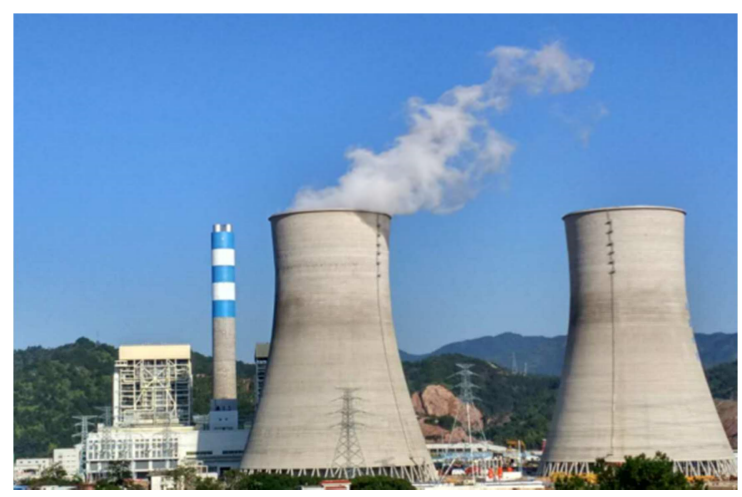

Figure 5. Operation effect of low-low-temperature technology in Dabu Power Plant.

\section{Application Effects}

Through joint efforts of each party, Unit 1\# and Unit 2\# of Yudian Dabu Power Plant was put into operation in December 2015 and May 2016 respectively and performs greatly.

According to the national standard, Guangdong Environmental Monitoring Center carried out the acceptance monitoring on Unit 2\# of Dabu Power Plant in August 2016, and the test report shows that the operating temperature of the low-low-temperature electrostatic precipitator is stabilized at $90^{\circ} \mathrm{C}$ and the outlet temperature of the post-stage heat exchanger of the $\mathrm{LGGH}$ is stabilized at $80^{\circ} \mathrm{C}$. According to the test on Unit 2\# by Nanjing Power Equipment Quality and Performance Testing Center on January, 2017, the low-low-temperature electrostatic precipitator has a dust density of $11 \mathrm{mg} / \mathrm{m}^{3}$ at its outlet, a dust removal rate of $99.92 \%$, a $\mathrm{SO}_{3}$ concentration of $6.6 \mathrm{mg} / \mathrm{m}^{3}$ and a $\mathrm{SO}_{3}$ removal rate of $81.8 \%$; in addition, the dusty density at the outlet of the EMP interception device, or the dust emission at the outlet of the chimney, is $2.3 \mathrm{mg} / \mathrm{m}^{3}$, a SO 3 concentration of $2.4 \mathrm{mg} / \mathrm{m}^{3}$ and a $\mathrm{SO}_{3}$ removal rate of $32 \%$ at the outlet of the EPM. The A\B precipitation efficiencies of the low-low-temperature electrostatic precipitators of Unit 2\# are $99.93 \% \sim 99.97 \%$ and 99.86 99.91\% respectively, the integrated precipitation efficiency of the unit is $99.94 \%$, and the smoke emission concentration at the outlet of the chimney is only $1.7 \mathrm{mg} / \mathrm{m}^{3}$. The dust emission effect of Yudian Dabu Power Plant not only conforms to the "Harshest-ever" standard Emission Standard of Air Pollutants for Thermal Power Plants formally implemented on July 1, 2014, but also meets the environmental protection requirements in Action Plan for Upgrading and Transformation of Energy Conservation and Emission Reduction of Coal Power issued on September 2014, five years ahead of schedule.

\section{Conclusions}

China's coal-centered resource consumption structure decides that the coal-fired units will continues to be an important source of air pollution in a quite long time in the future. Therefore, ultra-low emission of the coal-fired units remains a major goal of upgrading and transformation of the 
power environmental protection, for which a high-efficiency, rational, reliable and economic ultra-low emission technology is of top priority. LGGH high-efficiency coal-fired flue gas treatment technology provides higher precipitation efficiency, energy conservation and emission reduction, and high-efficiency $\mathrm{SO}_{3}$ removal, solves the problem of "Gypsum rain" and visual pollution, and realizes dry chimney discharge. Through this example application in Yudian Dabu Power Plant, the high efficiency and reliability of LGGH is further verified. The LGGH high-efficiency coal-fired flue gas treatment technology has great potential to become a popular post-combustion flue gas treatment technology and deserves promotion at home and abroad.

\section{Acknowledgements}

This study is funded by National Key Technology Research and Development Program-Integrated Collaborative Ultra-clean Treatment Technology for Flue Gas of Coal-fired Power Plant and Project Example (2015BAA05B01), a subject of Low-low-temperature Electrostatic Precipitation Technology.

\section{References}

[1] Ministry of Environmental Protection and General Administration of Quality Supervision, Inspection and Quarantine of the People's Republic of China. GB13223-2011. Emission Standard of Air Pollutants for Thermal Power Plants [S]. China Environmental Science Press. 2011.

[2] National Development and Reform Commission, Ministry of Environmental Protection and National Energy Administration, Circular on Printing and Distributing Action Plan for Upgrading and Transformation of Energy Conservation and Emission Reduction of Coal Power (2014-2020) [EB/OL]. http://bgt.ndrc.gov.cn/zcfb/201409/t20140919_626242.html [2014-9-12].

[3] Zhan Liyong, Chen Zhaomei, Zhao Jinda, et al. Application of WESP on "Near-zero Emissions" Project of Coal-fired Power Plant $[\mathrm{J}]$. Electric Power Technology and Environmental Protection, 2016, 32(5): 16-18.

[4] Zhou Dan, China's Energy Mix will Gradually Shift to Clean
Power Generation [J]. Sino-global Energy.2018 (6).

[5] Yang Yongping, When Coal-dominated Situation will Stop? [J]. China Financial Weekly. 2018 (26).

[6] Yang Yingming, Sun Jiandong, et al. Current Status and Prospects of Optimization on Energy Mix Research in China [J]. Coal Engineering. 2019 (2).

[7] Long Hui. Development, Application and Prospect of Low-low-temperature High-efficiency Flue Gas Treatment Technology [C]. Conference of ESP. 2009.

[8] Liao Zeng'an. Discussion on Low-low-temperature High-efficiency Flue Gas Collaborative Control Application Technology of Coal-fired Power Plant [C]. Conference of ESP.2015.

[9] Cui Zhanzhong, Long Hui, Long Zhengwei, et al. Technical Features of Low-low-temperature High-efficiency Flue Gas Treatment System and Its Application Prospects in China [J]. Journal of Chinese Society of Power Engineering, 2012, 32(2): 152-158.

[10] The Electro Static Precipitator Committee of China Association of Environment Protection Industry, Ultra-low Emission Technology for Coal-fired Power Plants [M]. Beijing: China Electric Power Press, 2015.

[11] Pan Lixiang. Quality Factors of Desulphurization Gypsum of Coal-fired Power Plant and Their Influences on Gypsum Products [C]. China Desulphurization Technology and Desulphurization Gypsum and Desulphurization Slag Treatment and Utilization Conference. 2008.

[12] Zhong Lei. Research on Heat Exchanger and Heat Exchange System of Low-low-temperature Electric Dust Removal Technology [D]. Southeast University. 2015.

\section{Biography}

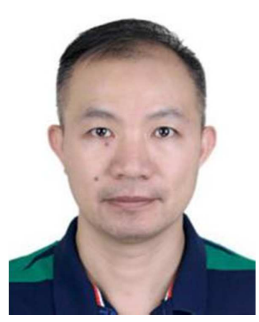

Liao Zeng'an, male, born in Longyan City, Fujian Province, is a professor-level engineer of Fujian Longking Co., Ltd. whose research interest lies in tail gas treatment of coal-fired boilers. 